\title{
PARADOXICAL COGNITION AND STRATEGIC DECISION QUALITY: THE MODERATING EFFECTS OF FLEXIBILITY AND RATIONALITY
}

\begin{abstract}
While recent research has provided valuable insight into how paradox facilitates dynamic decision making, the positive effect of paradoxical cognition on strategic decision quality has not been empirically tested, and its boundary conditions are unclear. We addressed these lacunae using survey data from 110 firms in China, an intriguing setting for studying paradox. We found the effect of paradoxical cognition on decision quality to be positive and significant. Furthermore, we found that firms adopting high levels of comprehensiveness and low levels of strategic flexibility benefit more from paradoxical cognition. We thus shed light on the boundary conditions of paradoxical cognition's positive effect on strategic decision quality: it is a complement to comprehensiveness, but is a substitute to strategic flexibility.
\end{abstract}

Key words: paradox, paradoxical cognition, strategic decision making, strategic flexibility, comprehensiveness, China. 


\section{PARADOXICAL COGNITION AND STRATEGIC DECISION QUALITY: THE MODERATING EFFECTS OF FLEXIBILITY AND RATIONALITY}

\section{INTRODUCTION}

Paradoxical cognition, defined as "managerial frames and processes that recognize and embrace contradiction" (Smith \& Tushman, 2005, p. 523), enables managers to consistently shift attention between differentiating and integrating practices (Smith \& Lewis, 2011). Paradox scholars propose that managing tensions through constant microshifts between, for instance, competing short- and long-term demands leads to more efficacious decision making (Smith, 2014; Smith, Lewis \& Tushman, 2016). Paradoxical cognition has been argued to promote superior outcomes in firms in relation to innovation (Andriopoulos \& Lewis, 2009; Lewis, Andriopoulos \& Smith, 2014), strategy and strategizing work (Costanzo \& Di Domenico, 2014; Dameron \& Torset, 2014), and strategic decision making (Calabretta, Gemser \& Wijnberg, 2016; Huq, Reay \& Chreim, 2016; Smith, 2014) - which is our focus in this study.

However, while recent qualitative studies have provided valuable insight into the role of paradoxical cognition in strategic decision making (Calabretta et al., 2016; Huq et al., 2016; Smith, 2014), the hypothesis that paradoxical cognition is positively associated with strategic decision making outcomes has not, to the best of our knowledge, been empirically tested. Moreover, the boundary conditions of this effect have not been clearly specified in prior research (Hargrave \& Van de Ven, 2016). A finer-grained understanding can be obtained by examining the moderating effects of two factors that are integral to the notion of paradox: rationality and flexibility. While paradox has been positioned as a contrast to a rational approach to decision making (Smith \& Lewis, 2011, p. 396), the interplay between rationality and paradox is under- 
researched (Calabretta et al, 2016). And although flexibility is viewed as inherent to paradox (Smith, 2014) the nature of flexibility in paradox is treated somewhat narrowly in terms of microshifts between competing tensions rather than a more broad-based resource allocative flexibility, for instance. As such, it is unclear whether firm-level strategic rationality and flexibility would dampen or amplify the effects of paradoxical cognition on decision making.

Drawing upon the literature on strategic decision making process (SDMP) is useful in addressing these deficiencies. First, in terms of testing the direct effect of paradoxical cognition on decision-making, SDMP research offers a useful outcome variable viz. decision quality, which is defined as a measure of coherence and accuracy in achieving organizational goals (Mustakallio, Autio \& Zahra, 2002; Payne, Bettman \& Johnson, 1993). Second, a rational approach to strategic decision making has been studied extensively in SDMP research; arguably its archetypical construct is comprehensiveness (Forbes, 2007), which refers to "the extent to which an organization attempts to be exhaustive or inclusive in making and integrating strategic decisions" (Fredrickson, 1984, p. 447). A rational perspective implies that a decision maker relies on information collection and its analysis in order to make the optimal choice from several alternatives in the given circumstances (Dean \& Sharfman, 1993; Nutt, 1998). Third, SDMP research highlights firms' disposition to strategic flexibility (Shimizu \& Hitt, 2004), defined as “the organization's capability to identify major changes in the external environment, quickly commit resources to new courses of action in response to those changes, and recognize and act promptly when it is time to halt or reverse existing resource commitments" (Shimizu \& Hitt, 2004, p. 44). While on the face of it, this construct might appear to be subsumed by the notion of paradox, strategic flexibility differs from paradoxical cognition; the former deals with an ex ante propensity to 
undertake macroshifts in allocating and reorganizing significant resources (Nadkarni \& Narayanan, 2007; Sanchez, 1995) whereas the latter entails microshifts - relatively small adjustments compared to what is implied in studies on strategic flexibility during the process of engaging with paradoxical tensions (Smith, 2014).

Linking the research gaps in paradox research identified above with these SDMP constructs leads us to address the following research questions: (1) Are higher levels of firm paradoxical cognition associated with higher levels of decision quality? (2) Do comprehensiveness and strategic flexibility moderate the relationship between paradoxical cognition and decision quality? By considering interaction effects between paradoxical cognition and the SDPM constructs of comprehensiveness and strategic flexibility we are in a better position to shed light on whether firms adopting more or less comprehensive approaches benefit more, in terms of decision quality, from paradoxical cognition, and similarly, whether more or less strategically flexible firms benefit more from paradoxical cognition.

We addressed our research questions using survey data from 110 Chinese manufacturing and trading service firms. Not only does China hold great interest for management and organization scholars due to its active involvement in international business and distinct managerial practices (Quer, Claver \& Rienda, 2007), it is especially relevant for this research due to the specific attitude to paradoxes captured by the principle of Yin Yang (Zhang, Waldman, Han \& Li, 2015). As Keller, Loewenstein and Yan (forthcoming) report, Chinese people demonstrate a higher willingness to adopt paradoxical frames than Americans. This makes China a suitable place for studying paradox and gaining a better understanding of its role in strategic decision making. Indeed, it has been suggested that China offers "an ideal, initial context for examining approaches to paradoxes" (Zhang et al., 2015, p. 539). 
Our findings suggest that paradoxical cognition has a significant positive effect on decision quality. Furthermore, it is a complement to comprehensiveness (positive moderating effect) but a substitute to strategic flexibility (negative moderating effect). This study contributes to paradoxical cognition research, in particular the emergent stream focusing on strategic decision making (Calabretta et al., 2016; Smith, 2014), in two ways. First, to the best of our knowledge, this is the first empirical test of the hypothesis that paradoxical cognition is positively associated with decision quality. Second, the paper clarifies certain boundary conditions to paradox theory that have not received sufficient attention in the literature: somewhat counterintuitively, the effect of paradox on decision quality is stronger under high levels of comprehensiveness and low levels of strategic flexibility. Thus although rationality has been positioned as being in opposition to paradox, its manifestation in the form of comprehensiveness in fact amplifies the effects of paradoxical cognition. And when flexibility is unpacked, we find that flexibility in making macroshifts (strategic flexibility) dampens the effects of flexibility in making microshifts (paradoxical cognition). Third, we bring attention to a Chinese context as an important and insightful setting for exploring the role of paradox in strategic decision making (Eranova \& Prashantham, 2016; Zhang et al., 2015).

The study's findings have useful normative implications: firms struggling to attain high levels of strategic flexibility may still be able to achieve good decision quality if their CEOs utilize paradoxical cognition. Furthermore, the benefits of such a paradoxical mindset are amplified by comprehensiveness; thus paradox and rationality can in fact be mutually reinforcing. 


\section{BACKGROUND}

\section{Paradoxical Cognition in Decision Making}

Scholars' interest in studying paradox reflects a growing recognition of the existence of conflicting tensions in all kinds of human activities. Indeed, the world is full of various contradictions and inconsistencies, and they are inevitable and ordinary ingredient of our life. "Simultaneous presence of opposites (i.e. paradoxes) is part of everyday practice" (Clegg, da Cunha \& e Cunha, 2002, p. 499). Individuals, groups and organizations are "inherently paradoxical" (Lewis, 2000, p. 760). Paradox represents "an ongoing challenge to our understanding of organizational processes and practices" (Jarzabkowski, Lê \& Van de Ven, 2013, p. 2). All organizations stand on paradox, and thus paradox is evident (Clegg et al., 2002, p. 483).

Paradox is "persistent contradiction between interdependent elements" (Schad, Lewis, Raich \& Smith, 2016, p. 6). Acknowledgment of the fact that the inherent conflict of opposing elements cannot be resolved and will persist over time is a core element of successfully managing paradoxes (Smith \& Lewis, 2011). In decision making, paradox involves alternatives that are simultaneously interdependent and contradictory, which requires leaders to be able to both separate and connect conflicting forces (Smith et al., 2016).

Specifically, paradox has been associated with dynamic decision making - an important process in ambidextrous organizations (Smith, Binns \& Tushman, 2010; Smith \& Lewis, 2011). It implies the simultaneous pursuit of exploration and exploitation: the constant shifting of resources, roles and responsibilities between these two activities, which is revealed in the organization's ability to make fast, frequent and flexible decisions (Smith et al., 2010). Dynamic decisions are also represented as "consistent inconsistency" that allows managers to making decisions in the short term 
while accepting contradicting tensions in the long term (Smith \& Lewis, 2011, p. 392). Following this notion of "consistent inconsistency," Smith (2014, p. 1617) proposes the "dynamic decision making model" which is characterized as "an alternative approach for decision making". The distinctive feature of this model is shifting a focus from a single short-term issue to a pattern of decisions in a long-term perspective and embracing inconsistencies between decisions. This model comprises three ways to address the tensions: choosing, accommodating and accepting. Within one decision pattern, some single choices made on the basis of "either/or" logic coexist with others that create a new synergy by accommodating conflicting alternatives. As Smith (2014, p. 1616) argues, "these decisions are not consistent with one another; rather, they shift in their support between contrasting demands over time".

Smith and Tushman (2005) emphasize situational and cognitive aspects of paradox. In their framework (2005) paradox occurs when tensions in a situation are juxtaposed in an individual's cognition. Paradoxical cognition refers to the ability to embrace contradictions (Schad et al., 2016). Leaders who think paradoxically identify a tension, explore its contradicting elements and links between them, and get new insights into existing problem (Lewis et al., 2014). Embracing paradox allows them to see the potential relationship between contradicting situations as complementary and reinforcing (Miron-Spektor, Gino \& Argote, 2011). Due to their high sensitivity to contradictions and inconsistencies, decision makers with paradoxical cognitive frames are able to scan information broadly and consider a greater variety of it, focusing on both qualitative and quantitative data (Hahn, Preuss, Pinks \& Figge, 2015). Paradoxical frames "increase the breadth of attention and the accessibility of knowledge related to the different elements" (Miron-Spektor et al., 2011, p. 230) 
With the exception of Smith's (2014) recent work, the problem of paradox and the ability to recognize and embrace conflicting tensions in relation to decision making has largely been overlooked by scholars. Research on strategic paradoxes proposes that paradox plays an important role in organizational life and represents an inseparable part of managers' everyday activities (Andriopoulos \& Lewis, 2009; Lüscher \& Lewis, 2008). The cognitive aspects of paradox and its moderators have also received little scholarly attention (Hahn et al., 2015).

In particular, little is known about the ways paradoxical cognition interacts with other cognitive processes such as information analysis, generation and evaluation of alternatives. Although paradoxical cognition has often been discussed as a dimension of flexibility, it is not clear how it interacts with a specific type of flexibility accentuated by SDMP research - strategic flexibility. In addition, paradox has been conceptualized as an alternative to a rational view of decision making (Smith, 2014) and studied in relation to the interplay between rational and intuitive decision making (Calabretta et al., 2016), yet its interaction with rationality has not been empirically tested. In addition, scholars call for more research on positive as well as negative aspects of paradoxical thinking and exploring what actors can benefit from paradox more than others (MironSpektor et al., 2011). Investigating how paradoxical cognition relates to decision making process variables would help to gain a deeper understanding of the concept. Exploring paradox in SDMP would also aid in creating a complete picture of the ways top managers deal with conflicting tensions.

\section{Strategic Flexibility and Comprehensiveness in SDMP}

SDMP research is concerned with questions of how strategic decisions are made and implemented, and what factors affect this process (Elbanna, 2006). In order to 
understand how the process of decision making determines its effectiveness, scholars investigate the relationships between process variables. Of particular importance are two of them - strategic flexibility and comprehensiveness - that have been associated with positive decision making outcomes (Dean \& Sharfman, 1996; Sharfman \& Dean, 1997). These process variables reflect different aspects of decision making and have often been studied together (Kandemir \& Acur, 2012; Walter et al., 2008). The inclusion of both strategic flexibility and comprehensiveness in the analysis helps to create a complete understanding of the decision making process, which serves the goal of exploring the role of paradox in this process. We discuss each below.

Strategic flexibility is "at the heart of strategic decision making" (Starkey, Wright \& Thompson 1991, p. 166). Shimizu and Hitt (2004) identify three components of flexibility, each of which activates during a particular stage of the decision making process. In the beginning of the process, at the attention stage, managers should focus on the capability to consider negative feedback. Then, in the assessment stage, flexibility is expressed through the capability "to collect and assess negative data objectively" (Shimizu \& Hitt, 2004, p. 45). Finally, on the action stage, flexibility is revealed through "the capability to initiate and complete change in a timely fashion even in the face of uncertainty" (2004, p. 45). Flexibility allows decision makers to make choices between multiple alternatives and respond to diverse task conditions, which is why it "is generally viewed as a mark of intelligence" (Payne et al., 1993, p. $5)$.

The ability to make changes fast is the characteristic of flexibility that has been emphasized by both strategy and paradox researchers. Lewis et al. (2014, p. 60) define strategic flexibility as "quick and innovative responses to the dynamic competitive landscape". In paradox research, flexibility is often pictured as an attribute of paradox. 
Specifically, it is viewed as a mechanism that drives paradoxical cognition (Good \& Michel, 2013). Changing focus between conflicting tensions enables actors to think paradoxically (Smith \& Tushman, 2005). According to Smith (2014), dynamic decision making represents an aggregation of little "temporary and flexible" responses to tensions. Smith and associates (2016) mention "purposeful microshifts" that enable actors to change focus between competing demands frequently in the short term in order to satisfy such demands in the long term. In paradox research, flexibility is therefore understood as constant small-scale movements between contradicting elements that drive paradoxical dynamics.

However, in contrast to paradox research, the conceptualization of strategic flexibility by SDMP scholars implies macroshifts, rather than microshifts. Microshifts proposed by paradox research refer to frequent small-scale moves between inconsistent demands intended to sustain strategic paradoxes within one strategic decision (Smith, 2014; Smith et al., 2016). Strategic flexibility also usually refers to substantive changes between strategic choices in response to environmental fluctuations, including reversing an intended course of action relatively fast (Sharfman \& Dean, 1997; Shimizu \& Hitt, 2004). This can be associated with more substantial displacements, or macroshifts, rather than smaller changes within a singular decision. Macroshifts can represent moves between opposing and contradictory sides of a continuum, yet they do not serve the goal of sustaining paradox; rather, macroshifts are stimulated by the need to adapt quickly to situational changes. Indeed, flexibility implies allocating and reorganizing substantial resources - organizational, manufacturing or production (Sanchez, 1995; Zhou \& Wu, 2010). This clearly points toward large-scale changes that occur at higher levels than those illustrated by paradox research. Moreover, scholars emphasize the strategic character of changes that flexibility helps to precipitate (Nadkarni \& Herrmann, 2010; 
Sanchez, 1995), and link it with strategic thinking that should be distinguished from thinking at other levels (Nadkarni \& Narayanan, 2007). Such differences in the conceptualization of strategic flexibility thus call for a more precise investigation of its relationship with paradoxical cognition in SDMP.

In SDMP research, flexibility is discussed in relation to a combination of a wide range of managerial capacities that help to respond to environmental changes and enable actors to produce novel choices (Fernández-Pérez, García-Morales, \& Pullés, 2016; Sharfman \& Dean, 1997). Such representation of strategic flexibility by SDMP scholars makes it an important element of decision making, alongside with the element of rationality. The main assumptions of the concept of rationality refer to the collection of relevant information necessary for making a choice, and the reliance upon analysis of this information (Dean \& Sharfman, 1996). Rational model of decision making is characterized by analytical comprehensiveness, which refers to the ability to be exhaustive and inclusive in making strategic decisions (Fredrickson, 1984). In SDMP research, rationality is often conceptualized as comprehensiveness (Forbes, 2007). Comprehensiveness enables actors to gather, scan and analyze the information needed for generating alternatives, as well as to conduct quantitative analysis and consider multiple alternatives (Fredrickson, 1984; Miller, Burke \& Glick, 1998).

Comprehensiveness and strategic flexibility represent two key elements in the strategic decision making that ensure the effectiveness of decision outcomes: if the former helps actors to collect information and analyze it accurately, the latter enables them to consider new sources of information and make choice wisely. Kandemir and Acur (2012) demonstrated empirically that rationality has a strong direct effect on strategic flexibility. Thomas and Ambrosini (2015) emphasize the role of comprehensiveness in the process of materializing strategy and suggest that it represents 
not only formality in planning but also flexibility through stimulating a greater information search.

\section{HYPOTHESES}

Comprehensiveness and flexibility emphasize different cognitive activities, and thus reflect different facets of the decision making process. Therefore, in order to create a complete understanding of the role of paradoxical cognition in SDMP, it is necessary to test its relationships with each process variable towards decision outcomes. Decision quality has been taken as a dependent variable. It is a proximate measure of decision making effectiveness, which refers to the accuracy of decision making in terms of extent of achieving its goals (Dooley \& Fryxell, 1999; Mustakallio et al., 2002; Payne et al., 1993). The model below (Figure 1) illustrates proposed relationships between paradoxical cognition, comprehensiveness, strategic flexibility and decision quality.

\section{Insert Figure 1 about here}

\section{Paradoxical Cognition and Decision Quality}

Paradoxical leaders recognize the fact that, in a dilemma situation, contradictions cannot be resolved by choosing one option, as two opposing options are interrelated and complement each other (Lüscher \& Lewis, 2008). Paradox encourages actors "to think differently" and move to "higher level of abstractions" to seek connections between the opposite elements and eventually fosters active thinking and creativity (2008, p. 229). These mental activities initiate the "working through paradox" and help managers to "make sense of tenuous demands to reduce anxiety, escape 
paralysis, and enable action" (2008, p. 227). Therefore, paradoxical cognition allows decision makers to avoid cognitive stagnation and stimulates the search for ideas. These features may help managers to achieve better decision outcomes.

Paradoxical cognition enables actors to embrace conflicting demands, which in turn leads to original decisions. As Smith and Tushman (2005) propose, effective managing of contradictions is driven by cognitive activities - the processes of differentiating and integrating. Differentiating "involves recognizing and articulating distinctions" and integrating "involves shifting levels of analysis to identify potential linkages" (2005, p. 527). Considering both aspects of a tension stimulates leaders to search for novel solutions (Lewis et al., 2014). These processes help decision makers "explicitly look for ways that the contradictory strategies can help each other" (Smith \& Tushman, 2005, p. 527). By facilitating idea generation processes and integrating contradictions, paradoxical thinking allows leaders to find new concepts and atypical possibilities, which enhances their creativity (Miron-Spektor et al., 2011). Thus, it might be assumed that paradoxical decision makers are more likely to come up with innovative, unique, and therefore, better decisions.

In addition, these opposing and interrelated processes of integrating and differentiating trigger different skills simultaneously. This allows a decision maker to be able to shift focus from one cognitive activity to another, and to use the benefits of both. The decision making literature distinguishes between two contrasting decision modes automatic mode and deliberate mode, also labeled system 1 and system 2 (Evans, 2008). The former implies fast intuitive decisions and the latter refers to rational information processing. Although these two systems of thinking use distinctive processing modes and represent qualitatively different activities, they also have numerous interrelations (Schneider \& Shiffrin, 1977). Moreover, the combination of both ensures better quality 
decisions (Shah et al., 2012). It might be assumed that the processes of differentiating and integrating - the core mechanisms of paradoxical cognition - allow a combination of both decision modes, and thus, lead to better decisions.

Paradoxical cognition ensures more accurate decisions. The strategic decision making process can be violated by cognitive traps, such as confirmation bias and statusquo bias (Kahneman et al., 2011). To avoid these traps, managers are recommended to view a problem from different perspectives and to pay attention to other possible solutions (Hammond et al., 1998; Kahneman et al., 2011). Paradoxical cognition highlights differences of conflicting ideas and therefore helps decision makers to look at the situation from new angles. As Smith and Tushman propose, by "explicitly drawing distinctions, managers are less committed to existing categories or points of view. Rather, under these conditions, managers generate new categories and classifications" (2005, p. 527). Thus, paradoxical cognition stimulates dynamic information processing and prevents "anchoring bias" (Kahneman et al., 2011).

Paradoxical cognition reduces the fear of the gap between contrasting options and makes the decision maker more confident and optimistic about the simultaneous pursuit of alternatives. Accepting the existence of paradoxes also helps to eliminate stress and fear as actors can find emotional comfort with it (Smith \& Tushman, 2005). The specific features of paradoxical cognition discussed above lead to the following hypothesis:

Hypothesis 1: Paradoxical cognition is positively related to decision quality.

\section{The Interaction between Paradoxical Cognition and Comprehensiveness}

Comprehensiveness strengthens the positive effect of paradoxical cognition on decision quality through better structuring information, which helps to identify 
conflicting alternatives and the ways they can be integrated. Empirical studies provide rich evidence to demonstrate the key role of comprehensiveness in executives' decision making (Atuahene-Gima, \& Li, 2004; Meissner \& Wulf, 2014; Thomas \& Ambrosini, 2015). Specifically, comprehensiveness advances the decision making process through extensive search for relevant information and its analysis (Fredrickson, 1984; Forbes, 2005). Hahn et al. (2015) suggest that managers with paradoxical cognitive frames are able to gather more diverse information in decision making, yet are less structured and formalized in collecting information. It can be suggested that higher levels of comprehensiveness will help paradoxical decision makers to overcome this weakness and strengthen the ability to structure information by broad scanning and analysis. Calabretta et al. (2016) emphasize the link between paradoxical thinking and interwoven practices of structuring information and making connections: comprehensiveness in collecting and structuring information enables actors to make connections between the elements and arrive at innovative solutions. It can therefore be argued that comprehensiveness helps decision makers to recognize contradictions faster and to identify the ways to combine contradictory ideas successfully. Extensive information search and analysis can strengthen the potential of paradoxical thinking to integrate opposing elements in unconventional ways and thus generate creative solutions (Miron-Spektor et al., 2011). Collecting more information, processing it carefully and structuring its elements in different orders increase the chances to find greater synergy between persistently contradictory ideas (Hahn et al., 2015). Therefore, comprehensiveness acts as a "fuel" that boosts the benefits of paradoxical cognition.

In addition, exhaustiveness and inclusiveness in decision making can help managers to address multiple conflicting tensions effectively. Dodd and Favaro (2006) identify a common problem of managers who face several tensions at one point in time 
and are unable to choose the most important one due to the interrelated nature of conflicting demands. While paradoxical managers focus on managing one specific tension exclusively, they might overlook other important contradictions that should be addressed concurrently. Comprehensiveness will allow them to consider various conflicting demands simultaneously, which is especially important since strategic decisions entail higher levels of complexity (Elbanna, 2006). Specifically, constant broad information scanning will help to identify several contradicting elements hidden in different aspect of a strategic decision. By carefully searching for information and thoroughly analysing it, managers will be able to keep their attention at different tensions and identify their linkages quickly, which eventually will help them to manage several tensions successfully. The above arguments lead to a following hypothesis:

Hypothesis 2: The relationship between paradoxical cognition and decision quality is stronger at high levels of comprehensiveness.

\section{The Interaction between Paradoxical Cognition and Strategic Flexibility}

Microshifts of paradoxical cognition might not fit macroshifts of strategic flexibility. Although both constructs have been associated with success in the long term (Lewis et al., 2014; Nadkarni \& Herrmann, 2010), it can be argued that the ways in which each construct helps actors to achieve positive outcomes in strategic perspective are not identical. While paradoxical cognition is realized through frequent moves between the poles of a tension in the short term in order to sustain paradox in the long term (Smith et al., 2016), strategic flexibility is associated with a relatively smooth and fast reallocation of resources that possess strategic importance to an organization facing environmental changes (Nadkarni \& Narayanan, 2007; Zhou \& Wu, 2010). Sanchez (1995, p. 138) distinguishes between resource and coordination aspects of strategic 
flexibility, arguing that flexibility "depends jointly on the inherent flexibilities of the resources available to the firm and on the firm's flexibilities in applying those resources to alternative course of action". The changes in reorganizing resources of strategic flexibility can take various forms depending on situational change. Switching from one course of action to another requires from an actor a certain degree of decisiveness and ability to fully concentrate on a particular option, as this process involves reallocation of a significant amount of resources. However, such changes do not necessarily imply shifts between contradicting alternatives and do not occur at a micro-level. Strategic flexibility is employed to respond to major changes and its value is in the ability to reallocate awkward-to-handle things in a relatively easy and quick fashion. In other words, paradox and strategic flexibility underpin different types of dynamics, which might require different capabilities and skills from decision makers.

In addition, due to principal differences in nature of their dynamics, it can be suggested that these two constructs represent two distinct approaches to tensions. If paradoxical cognition helps to embrace contradictions through microshifts within one strategic decision, flexibility stimulated by complex cognitive processes implies largescale moves of resources between strategic decisions, depending on situational changes. In other words, if paradoxical cognition refers to accepting tensions, strategic flexibility could be associated with switching between them. Human information processing system has a limited capacity (Simon, 1959). Therefore, integrating two approaches becomes challenging and the decision making task cannot be accomplished successfully. A manager loses time and resources trying to find a match between two different methods of solving problems. Therefore, instead of considering the actual decision, a manager thinks about how to decide, and thus gets stuck in a pre-solving stage that retards progression to the solving stage. This causes information overload $-\mathrm{a}$ 
situation of mismatch between information processing capabilities and the information load encountered (O’Reilly, 1980). Overload refers not only to information intensity, but also to its diversity and patterning, and is associated with stress and complexity (Milord \& Perry, 1977). The detrimental effect of information overload on decision quality has been discussed in the decision making literature (Chan, 2001; Chewning \& Harrell, 1990; Hwang \& Lin, 1999). The negative effects of information overload caused by the limited capacity of human information processing systems make a manager unable to accomplish a decision task (Simon, 1959). Therefore, when trying to integrate strategic flexibility and paradoxical cognition, instead of fully dedicating to one practice and enjoying its benefits, a manager's mind is divided between the two of them, and eventually does not use any. The combination of both approaches thus leads to managers being mentally paralyzed and unable to move further. As a result, a manager cannot concentrate on arriving at an optimal decision.

Therefore, high levels of each might harm the quality of a decision. Hence, a competing hypothesis can be proposed:

Hypothesis 3: The relationship between paradoxical cognition and decision quality is weaker at high levels of strategic flexibility.

\section{METHODS}

To test the hypotheses, a survey questionnaire method has been chosen. Despite several limitations of this type of design it remains one of the most common techniques in decision making studies (Meissner \& Wulf, 2014; Papadakis, Thanos \& Barwise, 2010). In addition to the methodological choices, decisions related to the process of data collection should involve considerations about the specifics of the empirical setting of a study. As discussed above, China is a unique country that has been developing 
relatively independently of Western influence over centuries. Despite its active involvement in international business with multinational corporations it remains a place with a distinctive culture which involves some specifics and difficulties for conducting research.

\section{Study Design and Data Collection.}

The sample population included around 680 manufacturing and trading companies across China, mainly from Zhejiang province. The population sample was built on the basis of multiple sources. Previous research pointed at a number of challenges in collecting data in emerging economies, especially in China, and advocated the use of various information sources (Batjargal, Hitt, Tsui, Arregle, Webb \& Miller, 2013). According to Batjargal and associates (2013) there are no systematic company databases in these countries. Even if some databases could be found, access to them is very limited, especially for Western researchers. Therefore, researchers can use only publicly available sources (Batjargal, 2013). In this study, the information about manufacturing and trading service companies was obtained from online resources, major industrial exhibitions in Guangzhou, Shanghai and Ningbo. The help of industry informants was also used.

The study adopted a few sampling criteria in the data collection process. To begin with, the primary activity of the company had to be manufacturing, import and export business, or both. Following that, all companies had to be located in Mainland China and owned domestically. Finally, a participant had to be a person involved in

strategic decision making processes as much as possible, preferably a CEO or a President (an owner of the business). In small- and medium-size companies the same person usually occupies both positions. The questionnaire was first developed in 
English, then translated in Chinese language by professional translators, and then backtranslated in English. The instrument was peer-reviewed and pilot-tested. The instrument was peer-reviewed and pilot-tested among 8 volunteers ( 2 academics, 1 doctoral researcher, 5 managers). Each participant was asked to provide individual feedback and identify potential problems. Specifically, attention was directed to the following points: whether all questions understood well, whether the meaning of all words was clear, and how long it took to complete the questionnaire. After improving and making minor changes the survey was distributed among the sample population.

Despite China's economic and political reforms, there are still a number of constraints on researchers conducting fieldwork (Thøgersen \& Heimer, 2006; Quer et al., 2007). Researchers have to diversify the sources of information in data collection and the methods of collecting data. In conducting this research project, several methods of approaching respondents were employed. During the first stage of data collection the questionnaire was administrated through emails and telephone calls. All respondents were informed about the confidentiality of all the information they would provide in the questionnaire. Over the summer of 2014, trained interviewers who were Chinese undergraduate students conducted telephone interviews. However, this method did not demonstrate high efficiency, as the response rate was very low (less than 10\%). Therefore, it was decided that, in order to attract the industry, informants should be used in the administration of the questionnaire. Industry informants were people of Chinese nationality who did business in similar or related industries, and were regarded as more trustworthy by participants, compared to a Western-based researcher who was often considered as a stranger and an outsider. In parallel with this method, the researchers started visiting the companies and conducting interviews in person. This strategy demonstrated a higher degree of efficiency, and in November 2014 the data collection 
process was completed.

Combination of various methods in data collection resulted in an overall response rate of $22 \%$. By the end of the process 163 questionnaires were received. Among these 163 cases 53 were not appropriate for the study as they were filled by middle managers, or were only half-completed. After removing such cases and checking for outliers the sample size decreased to 110. Most of the companies (more than $80 \%$ ) had less than 250 employees and therefore belonged to the category of small- and medium-size enterprises (SMEs) according the definition of European Union which has been commonly used in research literature (Chetty \& Agndal, 2007; Wiklund \& Shepherd, 2003).

\section{Measures}

Most of the variables are operationalized identically to Elbanna and Child (2007) i.e. at the level of the decision. In adding the independent variables, strategic flexibility and paradoxical cognition, it was inevitable to draw on studies that operationalize these at the organizational and the individual level, respectively. However, this was not deemed a big problem because the types of companies included in this study typically involve owner-managers making decisions in relatively small firms. Thus it seems reasonable to assume that their decision making strategic flexibility and paradoxical cognition would hold at the level of the decision also (see Dooley \& Fryxell, 1999, for a similar approach).

Following Finkelstein and Hambrick (1996) and Hambrick (2007), previous research provided substantial evidence to suggest that a CEO personality has a dominant impact on the strategy formulation and organizational actions, which is typical for SMEs (Hsu, Chen \& Cheng, 2013; Li \& Tang, 2010; Nadkarni \& Herrmann, 
2010). Due to the high concentration of power aggregated by CEOs, their decisions determine main organizational activities and their outcomes. In addition, these features of CEOs have been associated with the high power distance cultures (Hsu et al., 2013), of which China is one (Hofstede, 2005). Thus, we believe that these characteristics of the sample allow us to focus on a firm level of analysis and to test the relationships between paradoxical cognition, strategic flexibility and decision quality.

Dependent and independent variables were measured by seven-point Likert-type scales ranging from 1 ("strongly disagree") to 7 ("strongly agree"). The measures were adapted from reputable studies published in top-level academic journals. Sample items are provided in a table below.

Insert Table 1 about here

Dependent variable. Decision quality was chosen to measure the dependent variable. To prevent the risk of common method variance, it is generally recommended that scholars obtain the measures for independent and dependent variables from different sources (Podsakoff et al., 2003). However, it is not always possible to achieve this in practice, especially if collecting data amongst privately owned companies in China. Researchers are often faced with restricted access to data in China (Quer et al., 2007; Batjargal et al., 2004). For example, archival sources to measure a dependent variable might not be available, and scholars must therefore rely on the responses of the same informants for measuring independent and dependent variables (Atuahene-Gima \& Li, 2004).

It should be noted that it is not uncommon to rely on self-rated data among scholars in the field of strategic decision making (Meissner \& Wulf, 2014; Forbes, 
2005; Slater et al., 2006). Although the high risk of social desirability and retrospective bias represents the disadvantages of using this measure (Podsakoff, MacKenzie, Lee, \& Podsakoff, 2003), there are also advantages to employing perceptual measures of a specific decision in comparison with objective measures. As Amason (1996) suggests, when using objective measures it is difficult to isolate for a single strategic decision, as this implies that several decisions had equal potential to generate successful outcomes. Therefore, as the author explains, "the best way to gauge the quality of an individual strategic decision is to ask those who have observed its effects and who understand its context to judge, retrospectively and on several dimensions, how the decision turned out" (Amason, 1996, p. 134). To ensure the reliability of the scales, the data from a second respondent within a subsample can be used. This is a common technique employed by strategic decision making scholars (Elbanna, 2015; Elbanna \& Child, 2007), and it was therefore decided that this technique would also be used in the current study.

Decision quality was measured using the four-item scales adapted from Dooley and Fryxell (1999). The items asked respondents about the quality of the information, the validity of the assumptions used for making the strategic decision, and the extent to which the decision fits with a current strategy of their company $(\alpha=.82)$.

Independent variable. Paradoxical cognition was measured using the scale items adapted from Miron-Spektor, Ingram, Keller, Smith and Lewis (2014), also been used by Keller et al. (forthcoming). In developing scales to measure paradoxical cognition Miron-Spektor et al. (2014) have identified the following three dimensions: awareness, embracing of paradoxes and positive affective reaction to paradoxes. Awareness of paradoxes is an ability to perceive, recognize and accentuate contradictions. Embracing of paradoxes is a capacity to view contradictions as being interdependent and existing 
simultaneously. Positive affective reaction to paradoxes refers to emotional lift and satisfaction when accepting contradicting demands. This study focuses only on the dimension of embracing of paradoxes, which reflects the essence of paradoxical cognition. Paradoxical cognition was measured with the four-item scale $(\alpha=.63)$ asking respondents to evaluate the extent to which they were willing to accept the contradictions that they face.

Moderating variables. Strategic flexibility $(\alpha=.84)$ was measured using the sixitem scales developed by Zhou and Wu (2010). The CEOs were asked to evaluate the extent to which they were able to reallocate and reorganize the resources of their company. As discussed above, the specifics of an empirical setting and the sample characteristics provide justification for including this variable in the analysis of the relationship between paradoxical cognition and decision quality. Comprehensiveness $(\alpha$ $=.80)$ was measured using the five-item scales adopted from Forbes (2005). The participants were asked how extensively their organization searched for information and analyzed it.

Control variables. The survey included several control variables: two respondent variables (gender, position in a company), three firm demographic variables (company size, company age, industry) and strategic decision variables (decision type, decision length, autonomy of a decision). Previous studies emphasized their importance and influence on decision making.

Scholars in the field of decision making often include CEO demographic characteristics in their studies (Li \& Tang, 2010; Papadakis, Lioukas \& Chambers, 1998; Zhu \& Chen, 2015). Research literature demonstrates that the style and the quality of decisions made by males and females differ significantly (Johnson \& Powell, 
1994). Therefore, we controlled for gender using a dummy variable $(0=$ male, $1=$ female).

Prior studies emphasize the strong influence of CEOs on the strategic decision making process, especially if the positions of chairperson and CEO are consolidated ( $\mathrm{Li}$ $\&$ Tang, 2010). It is assumed that, due to the high concentration of power, the owner of the company has a dominant influence on its decisions when compared to an executive who is a company employee. The questionnaire asked respondents to indicate their position in the company (owner) and to choose among the three options: CEO, President or both. We coded the position in a following way: $0=$ no (if position is CEO), $1=$ yes (if position is President or both President and CEO).

Company size may have an influence on decision making, as the processes in larger firms are expected to be more formalized (Fredrikson \& Iaquinto, 1989). We suggest that it can also affect the decision outcomes, as in larger firms the decision making process can be slower than in smaller ones, which eventually might have an impact on the quality of decisions. Company size was measured as a number of full-time occupied employees. Since the majority of the companies in this study were SMEs we decided to base on this fact in coding this variable: $0=$ small and medium size $(<250), 1$ $=(>250)$.

Research literature suggests that the decision making process in younger firms is more dynamic compared to older firms due to less formalized structures (Miller \& Chen, 1996). As with company size, we assume that company age can affect the decision outcomes. Company age was measured as number of years from a firm's establishment date to the year in which the data was collected (2014).

This study focuses on manufacturing and trading service firms. In China, companies often run these two businesses simultaneously. It can be suggested that the 
decision making process in firms involved in both manufacturing and trading is more complicated than in those that rely exclusively on trading. Trading companies are usually smaller in size and have a simpler structure. Industry type is often included by scholars interested in decision making in their analyses (Atuahene-Gima \& Li, 2004). The respondents where asked about the industry their firm belong to and to: manufacturing, trading service firm or both. The industry was measured as a dummy variable where $0=$ trading service without manufacturing, $1=$ manufacturing or both manufacturing and trading service.

Prior research suggests that strategic decision characteristics have a strong influence on the decision outcomes and therefore cannot be ignored (Elbanna \& Child, 2007; Papadakis et al., 1998). Specifically, it was found that the nature of strategic decisions plays an important role in the decision making process (Papadakis et al., 1998). Therefore, we controlled for decision type. The respondents were asked to provide some information about the strategic decision they made in their company. These descriptions allowed the researcher to define the type of each strategic decision in terms of exploration and exploitation. Thus, basing on March's (1991) distinction, exploitation decisions would imply reliance on existing knowledge, refinement and low level of risk, whereas exploration decisions could be associated with innovation, discovery and relatively high level of risk. For example, a typical exploitation decisions was "to find more overseas customers" or "to focus on domestic market", and such decisions as "to launch a new product" or "to enter European market" were considered as exploitation $(0=$ exploitation, $1=$ exploration $)$.

Decision speed has been often discussed in relation to decision outcomes (Bourgeois \& Eisenhardt, 1988; Judge \& Miller, 1991). Considering this, we controlled for the time spent developing a strategic decision. In addition to the brief description of 
the decision, the respondents had to indicate the date (month and year) when they started to consider possible alternatives for this decision and the date on which they made a final choice. Based on this information the length of the decision could be identified. Immediate choices were defined as choices made at the same time with initial evaluation of potential courses of action. Decision length was measured as the time difference between the moment of initial evaluation of alternatives and the moment of making a final decision: $0=$ no difference (immediate decision), $1=1$ month or more difference.

Respondents were also questioned about the number of people involved in the decision making process. Although CEOs play a dominant role in the strategic decision making process, it is very likely that other senior leaders and advisors are involved at some stages of the process, especially in collectivistic societies like China (Hofstede, 2005). Chinese SMEs often represent family enterprises and it is quite common for leaders to discuss their business with relatives. Considering these factors, it is assumed that active involvement of a CEO's in-groups increases the amount of information and therefore influences the quality of decisions. Consequently, we added decision autonomy into the analysis. The questionnaire asked the respondents to indicate if someone else was involved in the decision making process. Decision autonomy was coded in a following way: $0=$ no other people involved, $1=1$ or more people involved.

Common method variance. Scholars suggest statistical remedies such as marker variable approach to detect possible common method variance, (Schaller, Patil \& Malhotra, 2015). This approach consists of adding a theoretically unrelated variable into the instrument and testing its correlation with key variables. Following this approach, the survey included a question about participants' preferences to spend their holidays abroad. The analysis did not reveal strong correlations between the marker variable and 
other constructs $(r \leq .1)$, and thus suggested that common method variance was not likely to be a problem.

One of the most widely used statistical remedies to control common method variance refers to Harman's one factor test. It is a simple and straightforward technique (Malhotra, Kim \& Patil, 2006), which explains why it is commonly employed, even in recent studies (Elbanna, 2015; Meissner \& Wulf, 2014; Nell \& Ambos, 2013). However, like other techniques, this approach has its limitations (Malhotra et al., 2006). To run the test, all variables were entered into exploratory factor analysis. The unrotated factor analysis showed no singe dominant factor. This means that common factor variance does not represent an issue for this study (Podsakoff et al., 2003).

This study also followed the relevant statistical and procedural remedies employed by previous studies that relied on the same source when obtaining measures for both independent and dependent variables (Elbanna \& Child, 2007; Nell \& Ambos, 2013; Walter, Kellermanns \& Lechner, 2012). Furthermore, during the data collection stage the researcher ensured respondents' anonymity to avoid the effect of social desirability.

According to previous research (Elbanna \& Child, 2007), another important technique used to mitigate concerns stemming from a single-source dataset involves interviewing a second respondent from each company. For a subsample (20\% of a total sample) the data for dependent variable (e.g. decision quality) was obtained from a different informant ${ }^{1}$. Therefore, in each of 22 cases, which constituted $20 \%$ of a total

\footnotetext{
${ }^{1}$ Decision quality as measured by the second informant within a sub-sample was added as the second column to the correlation matrix. A side-by-side comparison of the correlations between the first two columns of the correlation matrix revealed some differences in a few variables. Perhaps this can be explained by some changes in magnitude between the two columns. However, this could also be interpreted as a signal of some degree of bias. A bigger size of the sub-sample could provide more definitive conclusions regarding the presence of common method bias. Unfortunately, a relatively small sample size does not allow the researcher to employ other techniques discussed in research literature, such as the unmeasured latent construct approach (Podsakoff, MacKenzie \& Podsakoff, 2012).
} 
sample, the second person in a company related to the strategic decision identified by the first respondent, and was asked about the quality of the same decision. To ensure confidentiality the respondents from each company did not have access to each other's answers. Perhaps the most straightforward way to assess the degree of consistency is to compare each pair of responses in each case individually and to calculate the percentage of agreement between the respondents. In most cases the level of agreement is above $80 \%$ and only three cases demonstrated a smaller percentage of agreement (74-76\%). Nevertheless, even $70 \%$ of agreement is regarded as acceptable (Rubin \& Babbie, 2011).

A common technique for assessing the level of agreement or consistency between different respondents is interrater or inter-observer reliability (IRR) (Rubin \& Babbie, 2011). Cohen's Kappa has been regarded as a common measure of IRR, however, it is only suitable for nominal data. The adequate alternative for ordinal data has been associated with intraclass correlation coefficient (ICC) (Hallgren, 2012; Shrout $\&$ Fleiss, 1979). The analysis showed the ICC value of .60, which is considered a good indication of IRR (Hallgren, 2012) and is comparable to the IRR results in other studies on strategic decision making (Elbanna \& Child, 2007).

\section{RESULTS}

Correlations are displayed in Table 2. To test the hypotheses, hierarchical ordinary least square (OLS) regression was conducted. The results are shown in Table 3. 
Control variables were entered at the first step, explaining only $22 \%$ of the variance in decision quality. Only one control variable (owner) had a significant effect on the dependent variable $(p<.010)$. Entering paradoxical cognition and SDMP variables in Model 2 added 24\% to the total variance explained which resulted in $\mathrm{R}^{2}$ of $.48, F(11,94)=7.98, p<.001$. As expected, paradoxical cognition (beta .28$)$ showed the strongest relationships among independent variables $(p<.01)$. Therefore, Hypothesis 1 was supported.

In Model 3, interactions of paradoxical cognition with comprehensiveness and strategic flexibility were added in a third block of regression in addition to control variables and independent variables. This resulted in the increasing of the total variance explained to $55 \%, F(13,92)=8.71, p<.0001$. As before, paradoxical cognition and showed a strong association with decision quality $(p<.010)$. Its interaction with comprehensiveness was positively significant $(p<.05)$, therefore, Hypothesis 2 was supported. However, the interaction effect of paradoxical cognition and strategic flexibility was negative (beta $-1.18, p<.010$ ). Therefore, Hypothesis 3 was supported. The interaction effects of paradoxical cognition and strategic process variables are displayed in Figure 2.

Insert Figure 2 about here

The results of the study indicate that paradoxical cognition plays an important role in SDMP. As expected, paradoxical cognition has strong direct and indirect positive effects on decision quality: it helps to achieve better outcomes and its effect on decision quality is strengthened by comprehensiveness. Arguably, the negative 
interaction between paradoxical cognition and strategic flexibility represents the most intriguing finding of this research.

\section{DISCUSSION}

Below we discuss the study's contributions, limitations and implications for research and practice.

\section{Contributions to the Literature}

Our findings advance the literature in several ways. First, we contribute to paradox theory by establishing the positive effect of paradoxical cognition on decision quality, which provides further grounds to suggest that paradox is essential to achieving organizational success. While paradoxical cognition has been previously noted to have a positive effect on other outcomes creativity and innovation (e.g. Andriopoulos \& Lewis, 2009; Miron-Spektor et al., 2011), to the best of our knowledge our study is the first empirical test of its positive effect on decision quality thus far posited mainly through conceptual or qualitative studies (e.g. Smith, 2014). Therefore, we contribute to paradox literature by shedding light on one of the positive consequences of adopting paradoxical thinking (Miron-Spektor et al., 2011).

Second (and even more importantly), we advance the paradox research stream by indicating boundary conditions of this positive effect (Hargrave \& Van de Ven, 2016; Miron-Spektor et al., 2011). It is greater when a priori strategic flexibility levels are low. This finding adds valuable nuance to extant understanding of flexibility in the paradox literature which focuses on microshifts between tensions rather than on macroshifts in resource allocation. These distinct forms of flexibility are substitutes. Additionally, we found a positive interaction effect between paradoxical cognition and 
the key SDMP variable - comprehensiveness. This clearly demonstrates that paradox plays an important role in the process of decision making and can be seen as a complement to comprehensiveness. In addition, this finding contributes to paradox research by extending the understanding of paradoxical cognition and showing which elements of decision making help to increase its potential. As comprehensiveness and strategic flexibility represent two different cognitive activities, these findings contribute to paradox literature by providing a better understanding of "the interplay between cognition and paradox" (Schad et al., 2011, p. 37). According to our results, the effect of paradoxical cognition is stronger if managers demonstrate high degrees of inclusiveness in information search and a reliance on information analysis. This means that although paradox represents an alternative approach to linear logic and the rational model of decision making in general (Smith, 2014; Smith \& Lewis, 2011), some elements of rationality (i.e. comprehensiveness) can actually amplify the positive role of paradox in the decision making process. As such, these findings allow scholars to get a more complete and nuanced understanding of paradox, resulting in more precise predictions of its outcomes in specific situations.

Third, we add welcome diversity to the empirical body of work informing paradox research by utilizing a Chinese context. Given the special attitude of Chinese people to paradox caused by the role and place of the Yin Yang philosophy in their traditional culture (Chen, 2008), it is especially important to see how it is perceived in its "natural" environment. It is informative to note that, even in a setting like China, CEOs vary in their levels of paradoxical cognition; thus, the capacity to embracing conflicting tensions cannot be assumed to exist in all CEOs and organizations simply because notions of paradox are deeply engrained in the culture. 


\section{Managerial Implications}

The results of this study showed that simultaneously pursuing conflicting tensions is possible and can benefit decision outcomes. Therefore, this research encourages managers to employ paradox in their decision making. However, it is important to grasp the meaning and the mechanism of paradox before employing it in strategic decision making. Assembling opposite alternatives in a mechanical way would not be appropriate here. To get the most out of paradox, a decision maker should understand how contradicting alternatives can benefit each other and how they can be integrated. It should be borne in mind that paradox does not imply an elimination of the tension, but directs them in a positive stream. It might be argued that integrating conflicting demands which will remain conflicting is challenging and hard to accomplish. However, applying "either/or" logic and trying to identify which of the contradictory choices will be better is not easier, and is time-consuming and inefficient. For many practitioners, paradoxical thinking may appear to be an unusual cognitive ability. However, grasping its essence can significantly improve decision outcomes because of its originality. Moreover, paradoxical attitudes to contradictions and its implementation in strategic decision making may help managers and organizations to build their competitive advantage.

The value of paradox should be particularly appreciated by those mangers who are not flexible enough or who cannot create the capacity for strategic flexibility due to the specifics of their business. Strategic flexibility has been regarded as one of the most important elements in achieving success (Shimizu \& Hitt, 2004). Nevertheless, in reality not all organizations can reorganize resources quickly. The ability to think paradoxically can help to compensate for the lack of strategic flexibility and to ensure high-quality decisions. The results of our study demonstrated that paradoxical cognition 
and strategic flexibility are substitutes. The specifics of their relationship lead to another practical suggestion, or perhaps a practical warning: care should be taken in attempts to be strategically flexible and paradoxical within the same decision. The equal abilities to reallocate resources according to environmental changes and to integrate conflicting tensions employed in solving the same strategic task might have a detrimental effect on decision quality. We therefore recommend that strategic flexibility and paradoxical cognition be used in different situations as this will create preconditions for a full realization of their individual potential. However, if this is hard to accomplish it might be recommended to be more inclusive and exhaustive in collecting and analyzing information to get a better decision.

\section{Limitations and Future Research Directions}

From the very beginning of the research process this study aimed to meet the criteria of high-quality and rigorous research, however some limitations were difficult to avoid. Most of them were caused by challenges related to data access and caused by the specifics of the empirical setting. Gaining access to the data represents one of the significant issues researchers commonly face, which is complicated by the present tough economic climate (Wilson, 2010). This issue is becoming even more challenging when doing research in emerging economies like China, and has been already noted by scholars (Batjargal et al., 2014; Quer, 2015; Wilson, 2010). Therefore, attempts to collect high-quality data from Chinese organizations always involve additional challenges.

The relatively small sample size $(<150)$ should be mentioned among the limitations of this study. The small sample size inherently puts some restrictions on the variety of the tools that can be employed in investigating relevant issues. In addition to 
that, cross-sectional design and reliance on the CEO as a single respondent in the quantitative study could be regarded as a limitation of this research. Cross-sectional design restricts our ability to infer causal effects of independent variables on dependent variable, whereas the impossibility to access other data to measure the dependent variable could result in single-source bias. This, however, is not uncommon for the studies in the field of strategic decision making (Elbanna \& Child, 2007; Garbuio et al., 2015; Meissner \& Wulf, 2014; Walter et al., 2012). We employed several remedies, inspired by previous studies (Elbanna \& Child, 2007; Walter et al., 2012), in order to minimize the negative consequences of these limitations. These included gaining the responses of other managers in the companies for a sub-sample (20\%) and applying Harman's one factor test. Future studies investigating paradox in the strategic decision making should try to find appropriate methodological solutions to increase the quality of research, such as ethnographic or action research.

Future research could further investigate the relationships between paradoxical cognition and strategic flexibility and the forms of their successful integration. Scholars should also try to analyze the effect of paradoxical cognition on other decision outcomes such as effectiveness or decision speed. Further attention should also be directed to investigating the implementation of paradoxical decisions.

Of course, the results of this study should be generalized to a wide range of contexts with caution since paradox may not be perceived in the same way in the East and West. It is possible that the substitutive nature of the relationship between paradoxical cognition and strategic flexibility found in our study could be explained by the influence of the empirical context of the study. For instance, due to the dominance of the principle of Yin Yang, the distinctions between paradoxical and flexible attitude to tensions may become more salient for Chinese managers than for their non-Chinese 
counterparts. Future cross-cultural research involving samples of both Eastern and Western CEOs would thus be very useful in establishing the generalizability of our findings.

That said, we maintain that this research represents valuable initial steps in exploring the role of paradox in strategic decision making and we hope it will inspire scholars to investigate this further. It might be suggested that decision making can be paradoxical in itself. Investigating various issues in strategic decision making within a paradox perspective represents a potential line of inquiry. Intriguing questions include: Can all contradictory demands be addressed in a paradoxical manner? In what cases is paradox not applicable? What types of paradoxical strategies to managing conflicting tensions could be identified? Addressing these issues will help deepen extant understanding of what paradox is, and what it is not. 


\section{REFERENCES LIST}

Amason, A. C. (1996). Distinguishing the effects of functional and dysfunctional conflict on strategic decision making: Resolving a paradox for top management teams. Academy of Management Journal, 39(1), 123-148.

Andriopoulos, C., \& Lewis, M. W. (2009). Exploitation-exploration tensions and organizational ambidexterity: Managing paradoxes of innovation. Organization Science, 20(4), 696-717.

Atuahene-Gima, K., \& Li, H. (2004). Strategic decision comprehensiveness and new product development outcomes in new technology ventures. Academy of Management Journal, 47(4), 583-597.

Batjargal, B., Hitt, M. A., Tsui, A. S., Arregle, J. L., Webb, J. W., \& Miller, T. L. (2013). Institutional polycentrism, entrepreneurs' social networks, and new venture growth. Academy of Management Journal, 56(4), 1024-1049.

Bourgeois III, L. J., \& Eisenhardt, K. M. (1988). Strategic decision processes in high velocity environments: Four cases in the microcomputer industry. Management Science, 34(7), 816-835.

Calabretta, G., Gemser, G., \& Wijnberg, N. M. (2016). The interplay between intuition and rationality in strategic decision making: A paradox perspective. Organization Studies, doi: 0170840616655483.

Cameron, K. S. (1986). Effectiveness as paradox: Consensus and conflict in conceptions of organizational effectiveness. Management Science, 32(5), 539553.

Chan, S. Y. (2001). The use of graphs as decision aids in relation to information overload and managerial decision quality. Journal of information science, 27(6), 417-425.

Chen, M. J. (2008). Reconceptualizing the competition-cooperation relationship: A transparadox perspective. Journal of Management Inquiry, 17(4), 288-305.

Chetty, S., \& Agndal, H. (2007). Social capital and its influence on changes in internationalization mode among small and medium-sized enterprises. Journal of International Marketing, 15(1), 1-29.

Chewning, E. G., \& Harrell, A. M. (1990). The effect of information load on decision makers' cue utilization levels and decision quality in a financial distress decision task. Accounting, Organizations and Society, 15(6), 527-542.

Clegg, S. R., da Cunha, J. V., \& e Cunha, M. P. (2002). Management paradoxes: A relational view. Human Relations, 55(5), 483-503.

Costanzo, L. A., \& Di Domenico, M. (2014). A multi-level dialectical paradox lens for top management team strategic decision-making in a corporate venture. British Journal of Management, 26(3), 484-506.

Dameron, S., \& Torset, C. (2014). The discursive construction of strategists' subjectivities: Towards a paradox lens on strategy. Journal of Management Studies, 51(2), 291-319.

Dean, J.W., \& Sharfman, M.P. (1993). Procedural rationality in the strategic decision-making process. Journal of Management Studies, 30(4), 587610.

Dean, J. W., \& Sharfman, M. P. (1996). Does decision process matter? A study of strategic decision-making effectiveness. Academy of Management Journal, 39(2), 368-392. 
Dodd, D., \& Favaro, K. (2006). Managing the right tension. Harvard Business Review, 84(12), 62-74.

Dooley, R. S., \& Fryxell, G. E. (1999). Attaining decision quality and commitment from dissent: The moderating effects of loyalty and competence in strategic decision-making teams. Academy of Management Journal, 42(4), 389-402.

Elbanna, S. (2006). Strategic decision-making: Process perspective. International Journal of Management Reviews, 8(1), 1-20.

Elbanna, S. (2015). Intuition in project management and missing links: Analyzing the predicating effects of environment and the mediating role of reflexivity. International Journal of Project Management, 33(6), 1236-1248.

Elbanna, S. \& Child, J. (2007). The influence of decision, environmental and firm characteristics on the rationality of strategic decision making. Journal of Management Studies, 44(4), 561-591.

Eranova, M. \& Prashantham, S. (2016). Decision making and paradox: Why study China? European Journal of Management, 34(3), 193-201.

Evans, J. S. B. (2008). Dual-processing accounts of reasoning, judgment, and social cognition. Annual Review Psychology, 59, 255-278.

Fernández-Pérez, V., García-Morales, V. J., \& Pullés, D. C. (2016). Entrepreneurial decision-making, external social networks and strategic flexibility: The role of CEOs' cognition. European Management Journal, 34(3), 296-309.

Finkelstein, S., \& Hambrick, D. C. (1996). Strategic leadership: Top executives and their effects on organizations. St. Paul: West.

Forbes, D. P. (2005). The Effects of Strategic Decision Making on Entrepreneurial Self-Efficacy. Entrepreneurship Theory and Practice, 29(5), 599-626.

Forbes, D. P. (2007). Reconsidering the strategic implications of decision comprehensiveness. Academy of Management Review, 32(2), 361-376.

Fredberg, T. (2014). If I say it's complex, it bloody well will be: CEO Strategies for Managing Paradox. The Journal of Applied Behavioral Science, 50(2), 171188.

Fredrickson, J. W. (1984). Strategic process research: Questions and recommendations. The Academy of Management Review, 8(4), 565-575.

Fredrickson, J. W., \& Iaquinto, A. L. (1989). Inertia and creeping rationality in strategic decision processes. Academy of Management Journal, 32(3), 516542.

Garbuio, M., Lovallo, D., \& Sibony, O. (2015). Evidence doesn't argue for itself: The value of disinterested dialogue in strategic decision-making. Long Range Planning, 48(6), 361-380.

Good, D., \& Michel, E. J. (2013). Individual ambidexterity: Exploring and exploiting in dynamic contexts. Journal of Psychology, 147(5), 435-453.

Hahn, T., Preuss, L., Pinkse, J., \& Figge, F. (2015). Cognitive frames in corporate sustainability: Managerial sensemaking with paradoxical and business case frames. Academy of Management Review, 4015(1), 18-42.

Hallgren, K. A. (2012). Computing inter-rater reliability for observational data: an overview and tutorial. Tutorials in Quantitative Methods for Psychology, 8(1), 23-34.

Hambrick, D. C. (2007). Upper echelons theory: An update. Academy of management review, 32(2), 334-343.

Hammond, J. S., Keeney, R. L., \& Raiffa, H. (1998). The hidden traps in decision making. Harvard Business Review, 76(5), 47-58. 
Hargrave, T. J., \& Van de Ven, A. H. (2016). Integrating Dialectical and Paradox Perspectives on Managing Contradictions in Organizations. Organization Studies, doi: 0170840616640843.

Hofstede, G. H. (2005), Cultures and Organizations: Software of the Mind, ( $\left.2^{\text {nd }} \mathrm{ed}\right)$, New York: McGraw-Hill.

Hsu, W. T., Chen, H. L., \& Cheng, C. Y. (2013). Internationalization and firm performance of SMEs: The moderating effects of CEO attributes. Journal of World Business, 48(1), 1-12.

Huq, J. L., Reay, T., \& Chreim, S. (2016). Protecting the paradox of interprofessional collaboration. Organization Studies, doi: 0170840616640847.

Hwang, M. I., \& Lin, J. W. (1999). Information dimension, information overload and decision quality. Journal of Information Science, 25(3), 213-218.

Jarzabkowski, P., Lê, J., \& Van de Ven, A. H. (2013). Responding to competing strategic demands: How organizing, belonging, and performing paradoxes coevolve. Strategic Organization, 11(3), 245-280.

Johnson, J. E. V. \& Powell, P. L. (1994). Decision making, risk and gender: Are managers different?. British Journal of Management, 5(2), 123-138.

Judge, W. Q., \& Miller, A. (1991). Antecedents and outcomes of decision speed in different environmental context. Academy of Management Journal, 34(2), 449-463.

Kahneman, D., Lovallo, D., \& Sibony, O. (2011). Before you make that big decision. Harvard Business Review, 89(6), 50-60.

Kandemir, D., \& Acur, N. (2012). Examining proactive strategic decision-making flexibility in new product development. Journal of Product Innovation Management, 29(4), 608-622.

Keller, J., Loewenstein, J., \& Yan, J. (forthcoming). Culture, conditions and paradoxical frames. Organization Studies.

Ketokivi, M. (2006). Elaborating the contingency theory of organizations: The case of manufacturing flexibility strategies. Production and Operations Management, 15(2), 215-228.

Lewis, M. W. (2000). Exploring paradox: Toward a more comprehensive guide. Academy of Management Review, 25(4), 760-776.

Lewis, M. W., Andriopoulos, C., \& Smith, W. K. (2014). Paradoxical leadership to enable strategic agility. California Management Review, 56(3), 58-77.

Li, J., \& Tang, Y. (2010). CEO hubris and firm risk taking in China: The moderating role of managerial discretion. Academy of Management Journal, 53(1), 45-68.

Lüscher L., \& Lewis, M. W. (2008). Organizational change and managerial sensemaking: Working through paradox. Academy of Management Journal, 5(2), 221-240.

Malhotra, N. K., Kim, S. S., \& Patil, A. (2006). Common method variance in IS research: A comparison of alternative approaches and a reanalysis of past research. Management Science, 52(12), 1865-1883.

March, J. G. (1991). Exploration and exploitation in organizational learning. Organization Science, 2(1), 71-87.

Meissner, P., \& Wulf, T. (2014). Antecedents and effects of decision comprehensiveness: The role of decision quality and perceived uncertainty. European Management Journal, 32(4), 625-635.

Miller, C. C., Burke, L. M., \& Glick, W. H. (1998). Cognitive diversity among upperechelon executives: Implications for strategic decision processes. Strategic Management Journal, 19(1), 39-58. 
Miller, D., \& Chen, M. J. (1996). The simplicity of competitive repertoires: An empirical analysis. Strategic Management Journal, 17, 419-439.

Milord, J. T., \& Perry, R. P. (1977). A Methodological Study of Overload. The Journal of General Psychology, 97(1), 131-137.

Miron-Spektor, E., Gino, F., \& Argote, L. (2011). Paradoxical frames and creative sparks: Enhancing individual creativity through conflict and integration. Organizational Behavior and Human Decision Processes, 116(2), 229-240.

Miron-Spektor, E., Ingram, A., Keller, J., Smith W., \& Lewis, M. (2014). Paradox mindset measure: Development and validation. Academy of Management Annual Meeting, Philadelphia, USA.

Mustakallio, M., Autio, E., \& Zahra, S. A. (2002). Relational and contractual governance in family firms: Effects on strategic decision making. Family Business Review, 15(3), 205-222.

Nadkarni, S., \& Herrmann, P. O. L. (2010). CEO personality, strategic flexibility, and firm performance: The case of the Indian business process outsourcing industry. Academy of Management Journal, 53(5), 1050-1073.

Nadkarni, S., \& Narayanan, V. K. (2007). Strategic schemas, strategic flexibility, and firm performance: the moderating role of industry clockspeed. Strategic Management Journal, 28(3), 243-270.

Nell, P. C., \& Ambos, B. (2013). Parenting advantage in the MNC: An embeddedness perspective on the value added by headquarters. Strategic Management Journal, 34(9), 1086-1103.

Nutt, P. C. (1998). How decision makers evaluate alternatives and the influence of complexity. Management Science, 44(8), 1148-1166.

O'Reilly, C. A. (1980). Individuals and information overload in organizations: is more necessarily better?. Academy of Management Journal, 23(4), 684-696.

Papadakis, V. M., Lioukas, S., \& Chambers, D. (1998). Strategic decision-making processes: The role of management and context. Strategic Management Journal, 19(2), 115-147.

Papadakis, V. M., Thanos, I., \& Barwise, P. (2010). Research on strategic decisions: Taking stock and looking ahead. In P. C. Nutt, and D. C., Wilson, (Eds.), Handbook of decision making, (pp. 31-69). Chichester: John Wiley \&Sons.

Payne, J. W., Bettman, J. R., \& Johnson, E. J. (1993). The adaptive decision maker. New York: Cambridge University Press.

Podsakoff, P. M., MacKenzie, S. B., Lee, J. Y., \& Podsakoff, N. P. (2003). Common method biases in behavioral research: a critical review of the literature and recommended remedies. Journal of Applied Psychology, 88(5), 879-903.

Podsakoff, P. M., MacKenzie, S. B., \& Podsakoff, N. P. (2012). Sources of method bias in social science research and recommendations on how to control it. Annual Review of Psychology, 63(1), 539-569.

Quer, D., Claver, E., \& Rienda, L. (2007). Business and management in China: A review of empirical research in leading international journals. Asia Pacific Journal of Management, 24(3), 359-384.

Rubin, A., \& Babbie, E. (2011). Research methods for social work. Belmont: Brooks/Cole empowerment series.

Sharfman, M. P., \& Dean J. W. (1997). Flexibility in strategic decision making: informational and ideological perspectives. Journal of Management Studies, 34(2), 191-217. 
Sanchez, R. (1995). Strategic flexibility in product competition. Strategic Management Journal, 16(S1), 135-159.

Schad, J., Lewis, M.W., Raisch, S., \& Smith, W.K. 2016. Paradox research in management science: Looking back to move forward. The Academy of Management Annals, 10(1), 5-64.

Schneider, W., \& Shiffrin, R. M. (1977). Controlled and automatic human information processing: I. Detection, search, and attention. Psychological Review, 84(1), 1-66.

Shah, S., Horne, A., \& Capellá, J. (2012). Good data won’t guarantee good decisions. Harvard Business Review, 90(4), 23-25.

Shepherd, N. G., \& Rudd, J. M. (2014). The Influence of context on the strategic decision-making process: A review of the literature. International Journal of Management Reviews, 16(3), 340-364.

Shimizu, K., \& Hitt, M. A. (2004). Strategic flexibility: Organizational preparedness to reverse ineffective strategic decisions. The Academy of Management Executive, 18(4), 44-59.

Shrout, P. E., \& Fleiss, J. L. (1979). Intraclass correlations: uses in assessing rater reliability. Psychological Bulletin, 86(2), 420-428.

Simon, H. A. (1959). Theories of decision making in economics and behavioral science. American Economic Review, 49(3), 253-283.

Smith, W. K. (2014). Dynamic decision making: A model of senior leaders managing strategic paradoxes. Academy of Management Journal, 57(6), 1592-1623.

Smith, W. K., Binns, A., \& Tushman, M. L. (2010). Complex business models: Managing strategic paradox simultaneously. Long Range Planning, 43(2), 448-461.

Smith, W. K., \& Lewis, M. W. (2011). Toward a theory of paradox: A dynamic equilibrium model of organizing. Academy of Management Review, 36(2), 381-403.

Smith, W. K., Lewis, M. W., \& Tushman, M. L. (2016). "Both/And” Leadership. Harvard Business Review.

Smith, W. K. \& Tushman, W. L. (2005). Managing strategic contradictions: A top management model for managing innovation streams. Organization Science, 16(5), 522-536.

Starkey, K., Wright, M., \& Thompson, S. (1991). Flexibility, hierarchy, markets. British Journal of Management, 2(3), 165-176.

Thomas, L., \& Ambrosini, V. (2015). Materializing strategy: the role of comprehensiveness and management controls in strategy formation in volatile environments. British Journal of Management, 26(S1), S105-S124.

Thøgersen, S. \& Heimer, M. (2006). Chapter 1. Introduction. In: M. Heimer and S. Thøgersen (Eds.), Doing fieldwork in China, (pp. 1-23). Copenhagen: NIAS.

Tushman, M. L., Smith, W. K., \& Binns, A. (2011). The ambidextrous CEO. Harvard Business Review, 89(6), 74-80.

Walter, J., Kellermanns, F. W., \& Lechner, C. (2008). Disentangling alliance management processes: Decision making, politicality, and alliance performance. Journal of Management Studies, 45(3), 530-560.

Walter, J., Kellermanns, F. W., \& Lechner, C. (2012). Decision making within and between organizations rationality, politics, and alliance performance. Journal of Management, 38(5), 1582-1610. 
Wang, T., Libaers, D., \& Jiao, H. (2014). Opening the black box of upper echelons in China: TMT attributes and strategic flexibility. Journal of Product Innovation Management, 32(5), 685-703.

Wiklund, J., \& Shepherd, D. (2003). Research notes and commentaries: knowledgebased resources, entrepreneurial orientation, and the performance of small and medium-sized businesses. Strategic Management Journal, 24(13), 1307-1314.

Wilson, D. C. (2010). The Bradford Studies: Issues raised by these and other studies for the understanding of decision making. In P. C. Nutt and D. C. Wilson (Eds.), The handbook of decision making, (pp. 619-642). Chichester: Wiley.

Zhang, Y., Waldman, D. A., Han, Y. L., \& Li, X. B. (2015). Paradoxical leader behaviors in people management: Antecedents and consequences. Academy of Management Journal, 58(2), 538-566.

Zhou, K. Z., \& Wu, F. (2010). Technological capability, strategic flexibility, and product innovation. Strategic Management Journal, 31(5), 547-561. 


\section{APPENDIX}

Table 1. Measurement items and validity assessment

\begin{tabular}{|c|c|c|c|}
\hline Variables & $\begin{array}{r}\text { Examples of items (1=strongly disagree, } \\
7=\text { strongly agree })\end{array}$ & $\begin{array}{l}\text { Composite } \\
\text { reliability }\end{array}$ & Source \\
\hline $\begin{array}{l}\text { Comprehensive- } \\
\text { ness }\end{array}$ & $\begin{array}{l}\text { 1. How extensively did the firm search for } \\
\text { information in making the decision? } \\
\text { 2. How extensively did the firm analyse the } \\
\text { relevant information in making the decision? } \\
\text { 3. How effective was the firm at focusing } \\
\text { attention on crucial information and ignoring } \\
\text { irrelevant information in making the decision?... }\end{array}$ & .80 & $\begin{array}{l}\text { Forbes } \\
(2005)\end{array}$ \\
\hline $\begin{array}{l}\text { Paradoxical } \\
\text { cognition }\end{array}$ & $\begin{array}{l}\text { 1. I often experience myself as simultaneously } \\
\text { embracing conflicting demands. } \\
\text { 2. Instead of trying to eliminate tensions I } \\
\text { accept them. } \\
\text { 3. When I consider conflicting perspectives I } \\
\text { gain a better understanding of an issue... }\end{array}$ & .92 & $\begin{array}{l}\text { Miron- } \\
\text { Spektor et } \\
\text { al., } \\
(2014)\end{array}$ \\
\hline $\begin{array}{l}\text { Strategic } \\
\text { flexibility }\end{array}$ & $\begin{array}{l}\text { 1. Redefining product strategies in terms of } \\
\text { which products the firm intends to offer and } \\
\text { which market segment it will target } \\
\text { 2. Reconfiguring chains of resources the firm } \\
\text { can use in developing, manufacturing, and } \\
\text { delivering its intended products to targeted } \\
\text { markets } \\
\text { 3. Redeploying organizational resources } \\
\text { effectively to support the firm's intended } \\
\text { product strategies... }\end{array}$ & .89 & $\begin{array}{l}\text { Zhou \& } \\
\text { Wu (2010) }\end{array}$ \\
\hline Decision quality & $\begin{array}{l}\text { 1.This decision was based on the best available } \\
\text { information. } \\
\text { 2.This decision was made based on valid } \\
\text { assumptions. } \\
\text { 3.This decision helps the firm achieve its } \\
\text { objectives... }\end{array}$ & .93 & $\begin{array}{l}\text { Dooley \& } \\
\text { Fryxell } \\
(1999)\end{array}$ \\
\hline
\end{tabular}

Figure 1. Model and hypotheses

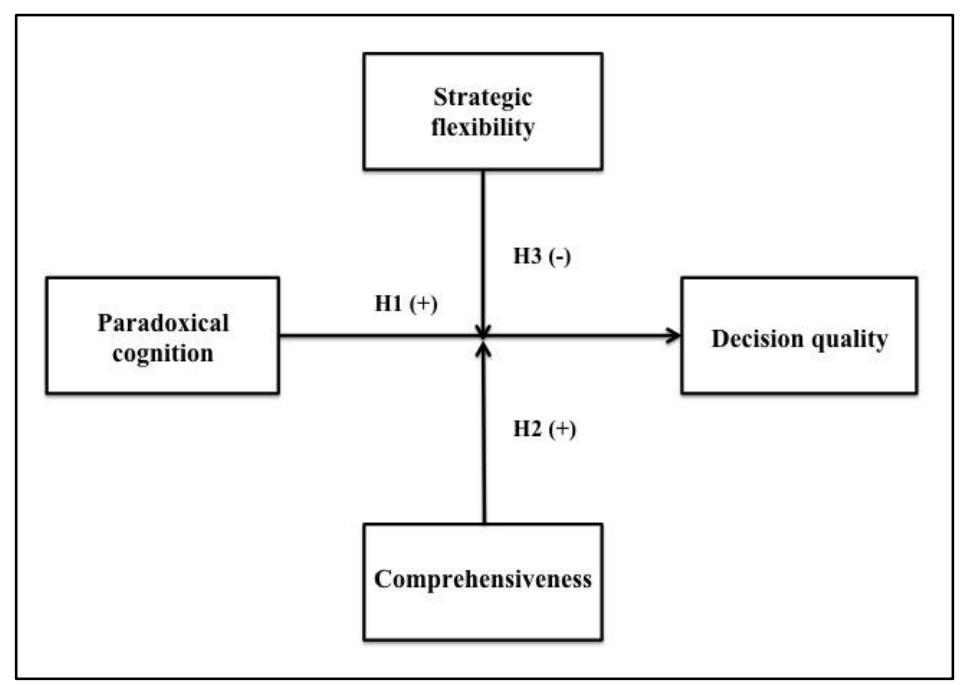


Figure 2. Interaction effects
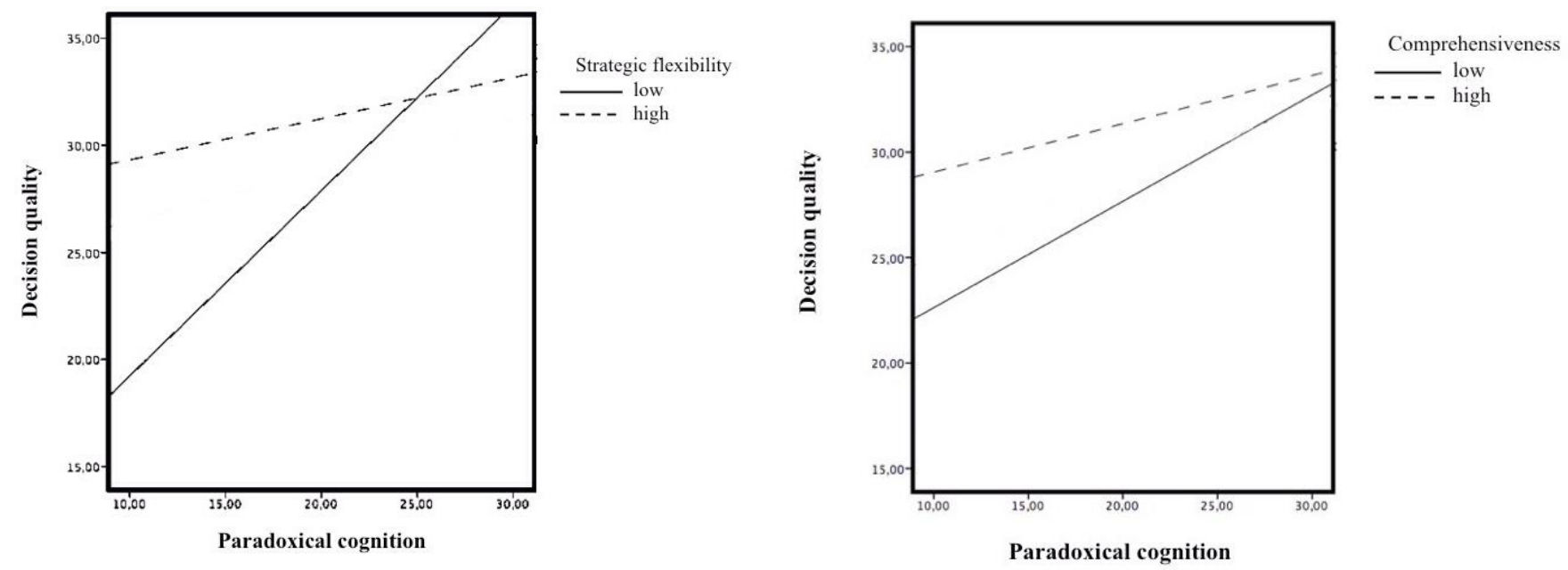

Table 2. Correlation coefficients

\begin{tabular}{|c|c|c|c|c|c|c|c|c|c|c|c|c|c|c|c|}
\hline & Variables & Mean & SD & 1 & 2 & 3 & 4 & 5 & 6 & 7 & 8 & 9 & 10 & 11 & 12 \\
\hline 1 & Decision quality & 29.14 & 4.34 & 1.00 & & & & & & & & & & & \\
\hline 2 & Gender & & & -0.06 & 1.00 & & & & & & & & & & \\
\hline 3 & Owner & & & $0.30^{* * * *}$ & -0.01 & 1.00 & & & & & & & & & \\
\hline 4 & Manufacturing & & & -0.06 & -0.10 & 0.13 & 1.00 & & & & & & & & \\
\hline 5 & Company age & & & $-0.24 * *$ & 0.03 & $-0.13 *$ & $0.17 * *$ & 1.00 & & & & & & & \\
\hline 6 & Company size & & & 0.15 & -0.03 & $-0.05 *$ & $0.22 * *$ & -0.01 & 1.00 & & & & & & \\
\hline 7 & Decision type & & & $0.12 *$ & $0.26 * * *$ & -0.11 & -0.07 & -0.07 & -0.01 & 1.00 & & & & & \\
\hline 8 & Decision length & & & $-0.21 * *$ & -0.05 & $-0.20 * *$ & -0.01 & 0.11 & 0.02 & 0.10 & 1.00 & & & & \\
\hline 9 & Decision autonomy & 11.47 & 7.62 & 0.00 & 0.04 & $-0.19 * *$ & -0.01 & 0.04 & $0.11 * *$ & $0.22 * *$ & $0.22 * *$ & 1.00 & & & \\
\hline 10 & Paradoxical cognition & 20.17 & 4.05 & $0.48 * * *$ & -0.04 & 0.14 & -0.08 & -0.10 & 0.11 & 0.06 & -0.09 & 0.05 & 1.00 & & \\
\hline 11 & Strategic flexibility & 31.63 & 6.60 & $0.47 * * *$ & -0.11 & 0.12 & 0.07 & $-0.09 *$ & 0.14 & 0.02 & -0.02 & -0.10 & $0.27 * * *$ & 1.00 & \\
\hline 12 & Comprehensiveness & 20.45 & 4.48 & $0.45 * * *$ & 0.02 & 0.06 & -0.07 & $-0.13 * * *$ & $0.30 *$ & $0.14 *$ & 0.01 & $0.13 *$ & $0.39 * * *$ & $0.40 * * *$ & 1.00 \\
\hline
\end{tabular}

Statistical significance: $* * * p<0.01 ; * * p<0.05 ; * p<0.10$ 
Table 3. Regression models

\begin{tabular}{|c|c|c|c|c|c|c|}
\hline \multirow{2}{*}{ Variables } & \multicolumn{2}{|c|}{ Model 1} & \multicolumn{2}{|c|}{ Model 2} & \multicolumn{2}{|c|}{ Model 3} \\
\hline & $\mathrm{B}$ & SE & $\mathrm{B}$ & SE & $\mathrm{B}$ & $\mathrm{SE}$ \\
\hline Constant & 29.46 & 2.17 & 14.51 & 2.81 & 12.95 & 2.67 \\
\hline Gender & -1.14 & 0.97 & -0.57 & 0.81 & -0.44 & 0.77 \\
\hline Owner & $2.58 * * *$ & 0.84 & $1.77 * *$ & 0.70 & $1.78 * *$ & 0.68 \\
\hline Manufacturing & -1.25 & 1.09 & -0.70 & 0.91 & -1.24 & 0.89 \\
\hline Company age & -0.08 & 0.05 & -0.06 & 0.04 & -0.06 & 0.04 \\
\hline Company size & $2.00 *$ & 1.04 & 0.51 & 0.91 & 0.96 & 0.86 \\
\hline Decision type & $1.55^{*}$ & 0.85 & 0.97 & 0.71 & 0.85 & 0.67 \\
\hline Decision length & $-2.05^{*}$ & 1.10 & $-1.85 * *$ & 0.91 & -1.34 & 0.88 \\
\hline Decision autonomy & 0.78 & 1.80 & 0.75 & 1.51 & 0.96 & 1.43 \\
\hline Paradoxical cognition & & & $0.28 * * *$ & 0.09 & $0.35^{* * *}$ & 0.09 \\
\hline Strategic flexibility & & & $0.19 * * *$ & 0.06 & $0.21 * * *$ & 0.05 \\
\hline Comprehensiveness & & & $0.17 *$ & 0.09 & 0.13 & 0.08 \\
\hline Paradoxical cognition*Strategic flexibility & & & & & $-1.18 * * *$ & 0.33 \\
\hline Paradoxical cognition*Comprehensiveness & & & & & $0.70 * *$ & 0.31 \\
\hline$R^{2}$ & \multicolumn{2}{|c|}{0.219} & \multicolumn{2}{|c|}{0.483} & \multicolumn{2}{|c|}{0.552} \\
\hline Adjusted $R^{2}$ & \multicolumn{2}{|c|}{0.154} & \multicolumn{2}{|c|}{0.422} & \multicolumn{2}{|c|}{0.488} \\
\hline$F$ & \multicolumn{2}{|c|}{$3.398 * * *$} & \multicolumn{2}{|c|}{$7.977 * * *$} & \multicolumn{2}{|c|}{$8.713 * * *$} \\
\hline $\mathrm{N}$ & \multicolumn{2}{|c|}{110} & \multicolumn{2}{|c|}{110} & \multicolumn{2}{|c|}{110} \\
\hline
\end{tabular}

Statistical significance: $* * * p<0.01 ; * * p<0.05 ; * p<0.10$ 